many of the basic skills are common to both trainees and some skills are most appropriately gained in a specialist hospital setting, but this is not to deny the special requirements of the general practitioner trainee.

I would like to suggest that the College should now direct its attention to the improvement of training in psychiatry for general practitioners. This is not something that should be done in isolation but in conjunction with the Royal College of General Practitioners. Given that psychiatric morbidity is among the most common of conditions in the community, the ultimate goal must be that all GPs gain some post-graduate experience in psychiatry. It is important that this training should be appropriate. The available posts should be jointly approved by the two Colleges and associated with academic courses specifically designed for their needs, although selected experiences existing on current MRCPsych courses may also be appropriate. The achievement of these goals will, of necessity, be a fairly slow evolutionary process over some years. However, not only are these changes desirable but the changes that will arise from the process of 'achieving a balance' present an opportunity that should be grasped without delay.

University Hospital of South Manchester

Manchester

\section{Writer in residence in psychiatry}

\section{DEAR SIRS}

We were very interested in your interview with the poet Selima Hill (Psychiatric Bulletin, November $1988,12,491-493)$, and in particular her comment that there had been no serious consideration in the UK of appointing a writer in residence in a psychiatric setting.

In late 1988 the Literary Arts Board of the Australia Council awarded Fiona Place a grant to work as a writer in residence in the Psychiatry Unit of the Prince Henry Hospital in Sydney (a teaching hospital of the University of New South Wales). Although there have been previous grants to writers to work in hospitals in Australia, this is the first such appointment in a psychiatric setting in this country. Fiona commenced this five month appointment in February 1989.

Fiona has published both poetry and prose in highly regarded Australian literary journals in recent years. Her novel Cardboard, concerning the experience of a young woman with anorexia nervosa, will be published by Local Consumption Press in April 1989. She is uniquely suited for the position as, in addition to her highly regarded writing skills, she herself suffered from anorexia nervosa for eight years.

The main aim of the residency is to act as a catalyst or stimulus for patients, relatives and staff to express their experiences of psychiatric illness in their own words, either in poetry or prose form. In addition to working with individuals, Fiona will hold workshops on 'Writing yourself out of illness'.

We will be evaluating the response and attitudes of both patients and staff to this residency.

\section{School of Psychiatry}

PHILIP MitChell

University of New South Wales

NSW, Australia

Fiona Place

Writer in Residence, Psychiatry Unit

Prince Henry Hospital, Little Bay

NSW, Australia

\section{Multiple personality disorder-appeal for help}

\section{DeAR Sirs}

I am trying to find a psychiatrist in England who is familiar with the phenomenon of multiple personality disorder. I am currently involved in a situation with a British subject who may manifest this profile. Although your ICD-9 does not recognise this condition, the DSM-III has provisions for it and there is an international society dedicated to its study (International Society for the Study of Multiple Personality and Dissociation, 2506 Gross Point Road, Evanston, Illinois 60201 USA).

The British subject in question was the victim of physical abuse, emotional neglect and probably sexual abuse any time from infancy to age eight when he left the orphanage and was reunited with a family he never knew existed. The natural mother was not nurturing (in fact, was abusive) and the British gentleman left home at age 16. My concern for his welfare and the wish to avoid further complications has led me to do considerable research and thus uncover the possibility of multiple personality disorder to explain the adult behaviour I have witnessed as well as have experienced at his hands. Knowing full well the inaccuracy of diagnostic methods, I am trying to cull enough data and expert opinions so that whatever therapeutic route is taken will have a fine chance of success rather than be one that is merely taken for the sake of expedience.

Since I myself utilise homeopathic medical treatment, it would be an even greater find to discover a homeopathic psychiatrist with this multiple personality disorder expertise. Although I have already been cautioned that such a person is rare as hen's teeth, I pass along this wish anyway since you may be able to find someone like this for me.

34 Montgomery Lane

LYNN A. GOLD

Greenwich, Connecticut

06830 USA 